\title{
El paso del ferrocarril por San Bernardo: Segregación social y disrupción del espacio local (1857-1957)
}

\author{
Felipe Delgado Valdivia ${ }^{1}$ \\ Recibido: 4 de octubre de 2016 - Aceptado: 24 de octubre de 2016
}

\begin{abstract}
Resumen
Este artículo aborda el caso del paso del ferrocarril por la ciudad de San Bernardo, considerando los aspectos espaciales e históricos involucrados en la construcción de este trazado. Para ello se recurrió a fuentes históricas emanadas de la prensa local y de la documentación procedente tanto de las autoridades locales como a nivel país, así también de la Empresa de Ferrocarriles del Estado. El interés por realizar este estudio radica en la posibilidad de problematizar respecto a la idea, a veces preconcebida, del rol de desarrollo, fomento y modernidad atribuido a la construcción y expansión del ferrocarril en nuestro país.
\end{abstract}

Palabras clave: San Bernardo, ferrocarriles, desarrollo urbano, historia local.

The Passage of the Railway across San Bernardo: Social Segregation and Disruption of Local Space (1857-1957)

\begin{abstract}
This article approaches the case of the passage of the railway through the city of San Bernardo, considering the spatial and historical aspects involved in the construction of this route. For this purpose, the author used historical sources from the local press and documentation from both local and national authorities, as well as from the State Railways Company. The interest in carrying out this study lies in the possibility of problematizing the idea, sometimes preconceived, of the role of development, promotion and modernity, attributed to the construction and expansion of the railroad in our country.
\end{abstract}

Keywords: San Bernardo, railways, urban development, local history.

1 Chileno. Profesor de Estado. Doctor (c) en Historia, Pontificia Universidad Católica de Chile. Becario CONICYT. E-mail: felipedelgado27@gmail.com 


\title{
0 passo da ferrovia por São Bernardo: Segregação social e perturbação do espaço local (1857-1957)
}

\begin{abstract}
Resumo
Este artigo aborda o caso do passo da ferrovia através da cidade de São Bernardo, considerando os aspectos geográficos e históricos envolvidos na construção deste trecho. Para aquilo, foi necessário recorrer a fontes históricas emanadas da imprensa local e da documentação procedente tanto das autoridades locais como do país, assim também da Empresa Ferroviária do Estado. 0 interesse deste estudo reside na possibilidade de problematizar sobre a ideia, por vezes, preconcebida, o papel do desenvolvimento, fomento e modernidade atribuído à construção e ampliação do transporte ferroviário no nosso país.
\end{abstract}

Palavras-chave: São Bernardo, ferrovias, desenvolvimento urbano, história local.

"San Bernardo [... ] está situado en una hermosa planicie: á sus alrededores se extienden caminos fertilísimos y bien cultivados. Dista 16 kilómetros de la capital y está unido a ella por la línea del ferrocarril central" (Prado, 1905: 526). Esta es la descripción que a inicios del siglo XX realiza un contemporáneo sobre las características topográficas y de asentamiento de una ciudad como San Bernardo, considerada antaño como la primera al sur de Santiago, y, otrora, la primera parada del tren al sur, con su estación construida en 1868. Es que el paso del ferrocarril por esta comuna fue muy importante al permitir la comunicación con la capital y con el resto del país, asunto que no extraña si asumimos las bondades que posee este medio de transporte, el cual precisamente se concibió como una forma de conectar efectiva y convenientemente el territorio (Sagredo, 2001: 90-91). Sin embargo, la presencia del ferrocarril en esta comuna generó alteraciones y dificultades provocadas con el transcurso de los años.

De acuerdo al arquitecto y urbanista Patricio Gross, el avance de la red de ferrocarriles sur generó transformaciones importantes en la morfología de los pueblos y ciudades del centro-sur del país que, dependiendo del impacto y ubicación de las estaciones y equipamiento ferroviario, jugó un rol decisivo en la modificación de la estructura interna de estos asentamientos (Gross, 1998: 9-14). Siguiendo esta tesis, la construcción de la red central de ferrocarriles significó para el caso de San Bernardo una escisión de su continuidad espacial, produciendo serios conflictos de accesibilidad, comunicación y seguridad, viéndose una zona de la ciudad (el sector oriente) más perjudicada que la otra (el sector poniente), en donde se ubicaba el centro cívico e histórico de la ciudad (Gross, 1998: 11-12). A las dimensiones territoriales y urbanísticas aportadas por el estudio de Gross, el trabajo que a continuación se presenta intentará sumarle el componente social e historico que deriva 
del paso del ferrocarril por San Bernardo y de la división espacial que éste generó, ocupando diversas fuentes, la mayor parte de ellas procedentes de documentación local, diarios, periódicos, decretos y oficios municipales, los cuales, junto a los documentos y publicaciones aportadas por la Empresa de Ferrocarriles del Estado, permiten aproximarnos al impacto de la llegada del ferrocarril a una realidad local.

\section{Opiniones divididas: La estación de San Bernardo y el paso del ferrocarril por la ciudad}

Después del hito que significó la inauguración del primer ferrocarril en Chile en 1851, que conectó a la ciudad de Copiapó con el puerto de Caldera, y el comienzo de los trabajos para trazar una vía férrea desde Valparaíso a Santiago, correspondió la tarea de extender este medio de transporte hacia el sur, cuestión que con el tiempo se tornó una de las empresas más rutilantes y encomiables llevadas a cabo por el Estado chileno a lo largo de su historia (Sagredo, 2000).

El tramo Santiago-San Bernardo fue el primero en inaugurarse dentro del extenso ferrocarril hacia el sur y significó, por parte del gobierno de la época, encabezado por Manuel Montt, una obra digna de celebrarse con toda pompa y rimbombancia, a la cual se sumó vivamente una multitud que atestó los andenes de la Estación Alameda para presenciar la salida del convoy (Escobar J., 1899: 5-7). El primer maquinista chileno, Manuel Jesús Escobar, fue testigo presencial de cuando el Presidente Manuel Montt inauguró el tramo del ferrocarril hasta San Bernardo, en septiembre de 1857, viajando a dicha ciudad en el tren y reuniéndose con las principales autoridades locales en un banquete en el que se "pronunciaron los más elocuentes discursos, aplaudiendo la inauguración del ferrocarril que establecía desde ese mismo día el tren ordinario de pasajeros, el cual continuó después con toda regularidad" (Escobar J., 1899: 8).

La inauguración del tren hasta San Bernardo sería la primera etapa de la extensa construcción del ferrocarril al sur, terminado medio siglo despues, y en el cual se incorporaron tanto capitales privados como estatales (Oppenheimer, 1976; Pinto, 1986: 49). Conocidos empresarios de la época como Enrique Meiggs, José Tomás Urmeneta y Matías Cousiño, fueron los primeros en involucrarse, junto al Estado, en el gran proyecto de extender un ferrocarril hacia el sur. La verdadera travesía que significó la extensión de este ferrocarril contó con su primer gran escollo cuando se vio enfrentado a las aguas del río Maipo, las cuales fueron atravesadas por un puente de 363 metros construido por Enrique Meiggs en 1859 (Thomson, Angerstein, 2000: 95). Luego de esto el tren se encaminó por la zona central del país, llegando 
el mismo año a la estación de Rancagua y de ahí seguió rumbo al sur, para, en 1913, alcanzar la ciudad de Puerto Montt, la cual sería la parada final del ferrocarril longitudinal sur. A lo menos en una primera etapa, la sociedad "Ferrocarril del Sur", encabezada por José Tomás Urmeneta y Matías Cousiño, y acompañada por el Estado, fue la encargada de la construcción de más de 200 kilometros de vías, las cuales en un lapso de 11 años alcanzaron a llegar hasta la ciudad de Curicó (1868) (Lacoste, 2000: 53).

Quienes se han aproximado al desarrollo histórico de los asentamientos humanos, coinciden en atribuir un rol importante a la construcción del ferrocarril en el crecimiento y transformación de éstos (Silvestri, 2004: 187-230), (Gross, 1998: 9-14), (Ramón, 1992: 187), (Moraga, 2001: 12), y particularmente, como dice José Luis Romero, "La estación del ferrocarril fue, como los puertos, un núcleo singular de desarrollo urbano" (Romero J. L., 2010: 225). En este sentido, el caso de la estación de San Bernardo resulta paradójico y un contraste si consideramos el significado del paso del ferrocarril por este pueblo y el estado en que se mantuvo este recinto durante gran parte de su existencia ${ }^{2}$. Aunque para ser justos, muchas de las estaciones de ferrocarriles del país se encontraban en las mismas condiciones que la de San Bernardo, suponiendo un estado de abandono y de deficiencia que las mismas autoridades del país asumían (Vicuña, 2013: 265-266). Construida en 1868, hasta las primeras décadas del siglo XX "...la estación de ferrocarriles de San Bernardo fue un espacio público que llenó de orgullo a la comunidad, simbolizando el progreso para este pueblo y transformándose en un lugar de esparcimiento donde las familias de la ciudad acudían para realizar su paseo matutino. Luego [...] este recinto se entregó al descuido y abandono de las autoridades, las cuales lo mantuvieron en un estado muy precario" (La Opinión, 25-VII-1942: 2).

Tradicionalmente para San Bernardo, la estación de ferrocarriles fue un hito urbano dentro de la ciudad, tanto por su atractivo como paseo familiar, para ver el incesante paso de las locomotoras y sus convoyes, como por el activo movimiento comercial que allí se realizaba, constituido por la salida de la producción vitivinícola de la zona (Ferrocarriles del Estado, julio de 1920), la carga y descarga de ganado dirigido al matadero local y por la llegada de las telas y tejidos que surtían a las tiendas y a los comerciantes textiles de la ciudad (Ríos, 1999: 55-167). A pesar de lo dicho, y de acuerdo a lo informado por el Gobernador del Departamento de La Victoria, ya hacia fines del siglo XIX el edificio de la estación presentaba problemas y no ofrecía:

2 El Ferrocarril Santiago-San Bernardo mantuvo su tráfico de pasajeros de modo inalterable hasta entrado el siglo XX, a pesar de la competencia que representó la llegada de tranvías y las Ilamadas "góndolas" o carros hacia esta última ciudad (El Clarín, 25-III-1933). 
"comodidad de ningún jénero: su aspecto es vetusto i pobre para el centro de población a que está destinada, pues fue una de las primeras que se construyeron en dicha línea; las bodegas están en un estado ruinoso e inservible; las habitaciones de los empleados están formadas por un pequeño edificio bajo, estrecho i mal situado; carece de andenes para el embarque de los pasajeros i de establos para el desembarque i estadía de los animales" (La Victoria, 5-V-1889).

A esta opinión se sumaron otras que veían que en la estación de ferrocarriles "No existe un solo salón de espera para los numerosos pasajeros que acuden a la estación; dos tristes faroles alumbran los caminos de la estación al pueblo, no hai asientos sino unos viejos i enormes umbrales colocados a raíz de un suelo húmedo donde poder descansar" (La Victoria, 2-XI-1890). Ni siquiera el conocido maquinista chileno Manuel Jesús Escobar, que tan elogiosos palabras ofreció para la inauguración del ferrocarril Santiago San Bernardo, pudo esconder el calamitoso estado de la estación señalando que "solo era una casucha donde se espendían boletos", y que era insuficiente para acoger la aglomeración de pasajeros que se generaba (Escobar J., 1899: 8).

Figura 1: Estación de Ferrocarriles de San Bernardo

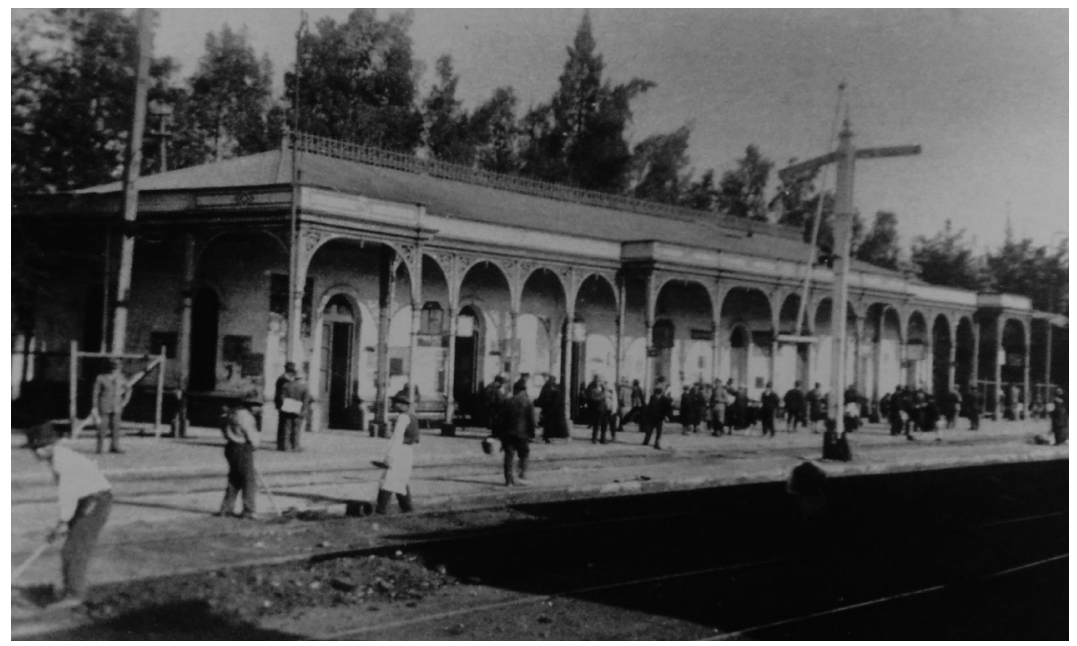

Fuente: Moraga, 200: 98

Pasados largos años, y recién en pleno siglo XX, se advierte intención formal de las autoridades por mejorar las descuidadas instalaciones de la estación de ferrocarriles (Diario La Opinión, 08-VIII-1942: 1). Para ello EFE ofrece un premio de $\$ 18.000$ a la estación de ferrocarriles mejor mantenida. Aun ante este oneroso estímulo, "En San Bernardo no se ha tomado interés 
por la iniciativa, ni por el ornato de la Estación. Frecuentemente la vemos desaseada y sus bodegas son un verdadero lunar" (El Debate, 30-VI-1945: 1). En definitiva, el edificio requería urgentes arreglos "porque es la estación de un pueblo de movimiento comercial y de un sitio privilegiado para los veraneantes que llegan acá en busca de reposo y salud" (Diario La Opinión, 1-VIII-1942: 2). Contradictoria a lo menos resulta una ciudad que, declarando una marcada tradición ferroviaria (Greve, 2012; Ortega, 2013), no haya procurado conservar y mejorar su estación de trenes que constituyó, a lo largo de los años, la primera impresión que los visitantes y viajeros poseían de las bondades y atractivos del tranquilo pueblo de San Bernardo, que en su momento se reveló como "el manso corazón de las antiguas familias chilenas que se ocultaban en achatados caserones de adobe y teja, para convivir una vida quieta, plácida y sin complicaciones" (Santiván, 1955: 133).

En 1908 comienza a funcionar el tranvía eléctrico que unió Santiago con San Bernardo, y por la misma época comienza la pavimentación del camino "La Polvareda", futura Gran Avenida, que era la principal vía de conexión con la capital para vehículos motorizados y de tracción animal. Si bien la construcción de estas dos obras apareció como una fuerte competencia para el transporte ferroviario, el caso es que pasados algunos años "La Empresa de Tranvías de San Bernardo ha pedido autorización para poner término a sus servicios y levantar sus instalaciones, en virtud de las enormes pérdidas que vienen esperimentando, por la competencia de los buses y los trenes locales" (El Clarín, 31-I-1931: 1). Por lo visto, resultaba difícil competir con la capacidad de transporte que poseían los ferrocarriles, que ofrecían además tarifas mucho más convenientes para movilizar a los pasajeros (El Clarín, 21-II-1931: 1-2). Lo anterior logra demostrar que aun ante una estación de trenes en estado ruinoso y casi abandonada, y frente a la irrupción de nuevos medios de transporte, el ferrocarril siguió siendo el vehículo de comunicación preferente para San Bernardo, en torno al cual la ciudad creció y se desarrolló.

\section{La división social}

"El martes de la presente semana un soldado que se encontraba en la estación del ferrocarril dio de palos a un vendedor por el solo hecho de atravesar por los balcones de un carro para pasar al otro lado del tren, como si no hubiera tenido boca para decirle que se bajara" (La Victoria, 2-XI-1890). Este episodio relatado en la prensa local nos remite al obstáculo que en su momento significó la línea del tren para San Bernardo, la cual separó a la ciudad en dos: por un lado, el sector poniente de la vía, el del casco histórico y centro cívico de la ciudad; por el otro, el sector oriente, aquél que aun bien entrado el siglo XX estaba poblado solo por casas quintas, chacras y calles sin pavimentar (Ríos, 1999: 63), y en donde un vendedor -el que aparece 
aludido en la noticia- le fue imposible deambular y cruzar libremente estas "dos ciudades", todo por la obstrucción del paso ferroviario ocupado por un tren y su convoy, el cual se opuso, cual verdadero muro, al transitar del sujeto, llamando la atención de la autoridad policial, quien castigó duramente el acto alevoso que significaba intentar sortear el ferrocarril. De acuerdo al historiador argentino Luis Alberto Romero, la ciudad de Santiago junto con suponer una segregación espacial también reproduce un proceso de segregación social entre la elite y los sectores populares (Romero, 2007). Parece ser que no solo en la capital se produjo este proceso de escisión, también en la comuna de San Bernardo ocurrió una situación muy similar.

"Se distinguían las clases sociales -relata un antiguo vecino de la comuna-. Era muy notorio en la Plaza de Armas que en el costado oriente [...] se paseaba la gente más acomodada, las señoras con sus familias, las niñas con sus pololos [mientras que] en el lado poniente [...] estaba la gente más proletaria" (Ríos, 1999, 79-80). El centro cívico de la ciudad fue el espacio tradicional en donde San Bernardo construyó su fama de ciudad aristocrática, lugar de sosiego para las familias de la elite santiaguina (Besoaín, 1995, 151-156).

Figura 2: Crecimiento urbano de San Bernardo y el paso del ferrocarril sur

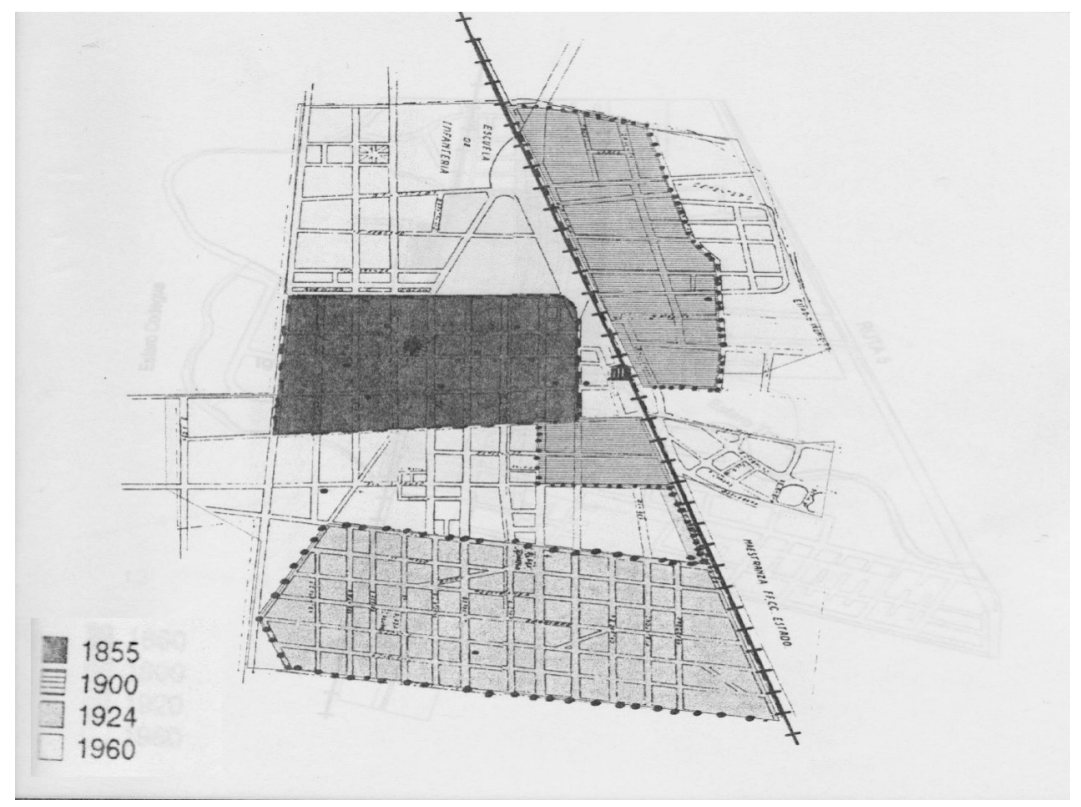

Fuente: Gross, 1998

Hasta entrado el siglo XX, esta ciudad no había alterado de modo significativo el trazado urbano de 32 cuadras sobre el cual evolucionó desde su fundación en 1821 (Besoaín, 1995: 95). La línea del ferrocarril fue durante 
el siglo XIX su límite oriente, el cual demarcó con mucha claridad el radio urbano de San Bernardo. Luego, una vez instalada la Maestranza Central de Ferrocarriles en 1920, con su imponente infraestructura, el sector oriente a la vía férrea comienza un creciente proceso de urbanización, de la mano con la solución habitacional para miles de obreros que buscaron asentamiento en la ciudad ante las condiciones de trabajo ofrecidas por la Maestranza. De tal modo que, una vez inaugurada, el emplazamiento de este gran taller ferroviario demarcó los límites urbanos de la ciudad hacia su lado oriente (véase Boletín Municipal, 30-IX-1926: 1-2), y agregó un contingente importante de trabajadores a este pueblo, por lo cual ganó fama de contar "con una de las más grandes poblaciones obreras de la República" (El Esfuerzo, 16-V-1925: 3).

Con la presencia de la Maestranza, sumado al efecto segregador de la línea del tren, la ciudad se divide claramente en la tradicional, por un lado, y la popular por el otro. Si bien los primeros conjuntos habitacionales para obreros se ubicaron en el margen sur de la ciudad, contigua a su trazado tradicional, posteriormente, junto al crecimiento urbano, y hacia la década de 1930, miles de trabajadores ferroviarios, junto a sus familias, encontraron colocación en el sector este de la ciudad, en barrios como la población Santa Marta, Ducaud, o Balmaceda, que se tornaron en zonas típicamente de clase proletaria (Gobernador de San Bernardo, 19 de junio de 1939; oficio 311).

Al proceso de urbanización que San Bernardo experimentó al otro lado de la línea, se opusieron los crecientes problemas sociales asociados a esto, que alertaron a las autoridades a tomar serias medidas al respecto. Como dijimos, el sector de la ciudad en donde se emplazó gran parte de la población de extracción más popular y obrera sería la zona oriente de ella. Junto a los trabajadores ferroviarios, fueron los del Haras Nacional y los del molino de la ciudad los que poblaron sucesivamente este sector (Gobernador de San Bernardo, 19 de junio de 1939; oficio 311). Este crecimiento poblacional, de acuerdo a las autoridades, propició la aparición de numerosos focos de inmoralidad y desórdenes, todos que ver con el masivo expendio de bebidas alcohólicas -muchos de ellos clandestinos- que crecieron en esta zona de la ciudad y en los alrededores de la Maestranza Central de Ferrocarriles (Gobernador de San Bernardo, 19 de junio de 1939; oficio 311); de ahí que el Gobernador del Departamento de La Victoria solicitará, mediante oficio, al señor Ministro de Agricultura declarar como zona seca todo el barrio oriente de San Bernardo, prohibiendo la venta de alcohol en la decena de bares y cantinas dispuestas en el lugar y clausurando aquellos recintos que expendían bebidas alcohólicas de forma clandestina (Gobernador de San Bernardo, 19 de junio de 1939; oficio 311). La solicitud del gobernador finalmente fue desestimada por la autoridad ministerial, quién tuvo mayor consideración por los argumentos entregados por la Prefectura Local de Carabineros en cuanto a que: 
"sería poco menos que imposible poder fiscalizar que en dicho sector no se expendieran bebidas alcohólicas, pues si bien es cierto que se terminaría con los negocios patentados, recrudecería el clandestinaje;

2) Al declararse zona seca el sector, a los negocios afectados por esta medida les sería muy fácil el cambiarse de local e irse a otra parte del pueblo donde no rija la mencionada zona seca, siguiendo siempre con el mismo giro;

3) En realidad, con esto no se llegaría a ningún resultado que diera efectos favorables y que por ende se justificara esta declaratoria de zona seca, pues las personas que desearan beber, solo tendrían que molestarse en andar un poco más, hasta encontrar un negocio patentado que las expenda:

4) Por otra parte, la práctica ha demostrado a los servicios de Carabineros, que las zonas secas solo dan resultados favorables en los centros mineros, industriales o agrícolas apartados, en donde es fácil de fiscalizar la ley, y

5) Finalmente en San Bernardo, y principalmente en el sector en que se desea declararlo zona seca, la 6a. Comisaría de esa localidad ha pasado 98 partes de Alcoholes, con lo que se prueba que allí se hace cumplir la Ley, a pesar de la escasez de personal con que se cuenta para el servicio..." (Tte. Coronel Domingo Pizarro, 26 de junio 1939; oficio 311).

Figura 3: Croquis de la zona de ley seca en San Bernardo

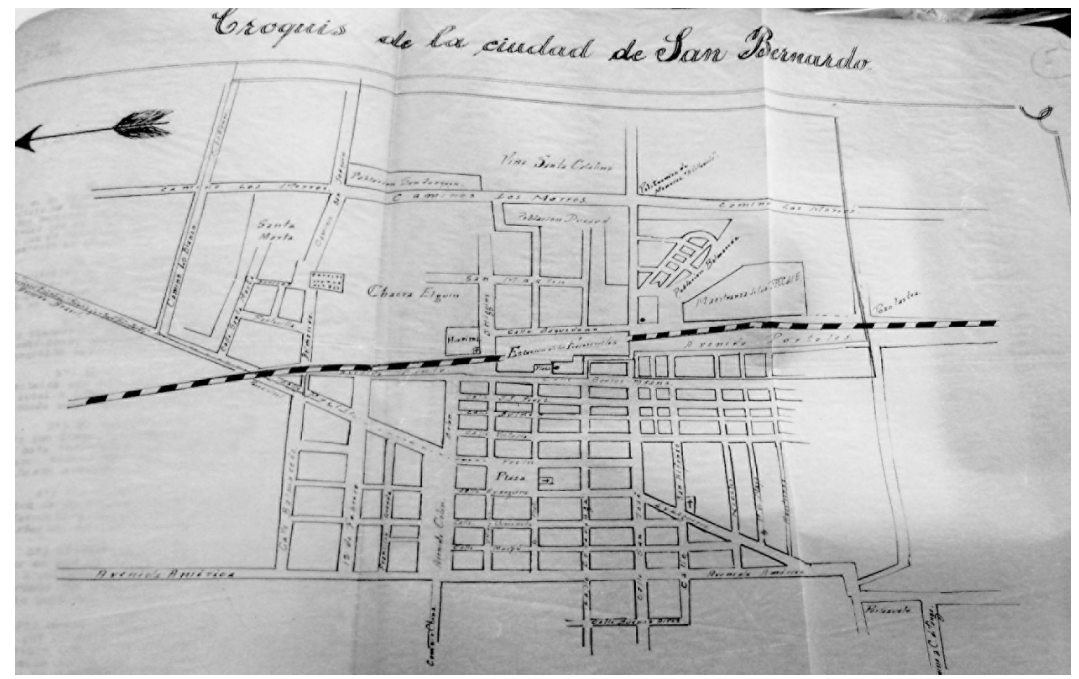

Fuente: Tte. Coronel Domingo Pizarro, 26 de junio 1939 
El croquis precedente, elaborado por la Prefectura de Carabineros de San Bernardo, ilustra la zona que, de acuerdo principalmente al Gobernador de San Bernardo, Don Galvarino Ponce, debía ser declarada zona seca por los constantes desórdenes y actos de inmoralidad que allí se producían ante la masiva venta de alcohol que se registraba en dicha parte de la ciudad. Como se puede advertir, siguiendo la línea punteada que se remarca sobre el plano de San Bernardo, la declaratoria de zona seca cubre prácticamente todo el sector que está al oriente de la línea del ferrocarril, sector que la autoridad finalmente entendía como peligroso y conflictivo, muy distinto a aquel sobre el cual se emplazaba el centro cívico e histórico de la ciudad. Pareció constituirse entonces, en torno al San Bernardo del otro lado de la línea, una mirada escandalizada, fundamentalmente construida por las autoridades locales, que vieron como en él alojaban las principales "fuentes de desórdenes, y [...] en ocasiones, la causa indirecta de delitos graves contra las personas o contra la propiedad" (Gobernador de San Bernardo, 19 de junio de 1939). Los episodios de desacato y alteración al orden público dieron cuenta del latente problema de marginalidad urbana que enfrentó la ciudad por esos años, a los cuales se sumó la queja de los vecinos por el descuido en que estaban inmersos los barrios periféricos, sobre todo los ubicados al oriente. Ejemplo de ello fueron las lamentaciones levantadas por algunos quienes habitaban en la población Ducaud, informando sobre la poca cobertura de servicios y mejoras que la Municipalidad de San Bernardo tiene que realizar en este barrio, quejándose que en sus calles no se realizaban adecuadamente las labores de aseo, que el alumbrado público es deficiente, e igualmente la presencia de efectivos de carabineros era escasa, sentenciando finalmente que "las rentas de la Municipalidad se emplean solo en beneficio de cierto barrio de la ciudad, en que viven algunos personajes de figuración"(llustre Municipalidad de San Bernardo, 1927; oficio 220). Ante este fuerte emplazamiento de un sector de los vecinos del pueblo, el municipio responde que "Los escasos fondos de que dispone la Municipalidad se distribuyen a medida de las necesidades, sirviendo como es natural, de preferencia, los barrios mas centrales, no porque habiten en ellos personajes de figuración, sino porque su movimiento y desarrollo así lo requieren" (Ilustre Municipalidad de San Bernardo, 1927; oficio 220).

Mientras tanto, ¿qué pasó con el otro sector de la ciudad? En dicho sector convivían casi armónicamente la actividad comercial junto con el tranquilo residir de las familias locales más tradicionales (Ríos, 1999: 21-22). Los García de la Huerta, los Dagnino, los Ossa o los Besoaín eran los clanes familiares que ocuparon tradicionalmente el casco histórico (Ibarra, 2007-2008), a pocas cuadras de la Plaza de Armas, y que eran acompañados en época estival por miembros de la elite santiaguina, quienes tenían aquí sus casas quintas y chalets de veraneo. Un sinnúmero de referencias son las que aluden a la condición de lugar de descanso de la cual gozó San Bernardo durante el siglo 
XIX y parte del XX, desatacando lo pintoresco de la ciudad que a inicios de la época estival se preparaba para:

"ser invadida por la selecta sociedad santiaguina que huye apresuradamente en busca de un clima fresco i agradable donde habitar.

Nuestro pueblo cada día toma más animación i se nota en el comercio i en sus calles i paseos mas movimiento.

A juzgar por el número de familias que ya se encuentran en esta, parece que en la presente temporada los veraneantes serán mui numerosos" (La Victoria, 15-I-1899).

No solo en este paisaje pintoresco y calmo se desarrollaba la vida en San Bernardo. El sector poniente a la línea de ferrocarriles representaba también el centro comercial del pueblo. Entre 1916 y 1917, de acuerdo a un catastro hecho por la municipalidad, de las 213 patentes comerciales entregadas entre esos años, 164 correspondían al rubro almacenes y mercaderías surtidas, y alrededor de las tres cuartas partes de estos negocios se ubicaban en las proximidades del centro cívico de la ciudad (llustre Municipalidad de San Bernardo, 12 de enero de 1917; Vol. 89; oficio 07). Sin sumar los restaurantes, hoteles y cantinas que también aportaban a la vida comercial del pueblo, en donde sus dueños eran parte importante de la elite local, residiendo en las manzanas que constituían el trazado tradicional de la ciudad (Ibarra, 20072008: 179-183).

\section{La división espacial y territorial}

Si el paso del ferrocarril por San Bernardo remarcó la segregación social del pueblo y se constituyó en un insoslayable obstáculo entre el barrio oriente y poniente de éste, por las mismas razones su trazado era también factor de riesgo y de accidentes. "El lunes último un tren de carga detenido en la Estación de los Ferrocarriles que obstruía como siempre el tráfico entre el barrio oriente y el centro, causó la horrorosa muerte a la señora Adela Venegas, mientras pretendió atravesar por debajo de los carros" (La Opinión, 4-X-1947: 3). Por lo visto, la escisión territorial de San Bernardo adquiría niveles dramáticos como los anteriormente relatados, y que eran advertidos claramente por los mismos habitantes de la comuna, que veían cómo "La estación y la línea del tren dividían a San Bernardo en dos ciudades; una grande, la del Poniente y otra pequeña, la del Oriente" (Rodríguez, 2007: 28). No menos dramáticas resultaba la ubicación del hospital de la ciudad en el lado nororiente a la estación de ferrocarriles, que a inicios del siglo XX era un sector bastante despoblado, y que encontraba al hospital "claustrado frente a la línea férrea i no tiene comunicación para su servicio que la que da 
acceso al costado Sur del paso a nivel" (La Victoria, 3-IX-1900). La apartada ubicación del hospital de San Bernardo generaba la constante preocupación tanto de las administradoras del recinto -Las Hermanas de la Caridad-como de sus pacientes, complicados por la incomunicación del edificio producto del paso de la línea del ferrocarril al costado poniente de éste (La Victoria, 3-IX-1900).

Pareciera que los intentos por mejorar el aspecto y las instalaciones de la estación de ferrocarriles eran infructuosos para aportar al desarrollo armónico de la ciudad. Por el contrario, habrían conspirado todavía más en la división espacial de ésta.

Las autoridades ferroviarias emprenden en 1915 una serie de trabajos que involucran a la estación de San Bernardo, la cual se ve intervenida por la ampliación de las líneas ante el inminente aumento del tráfico ferroviario por la apertura, contigua al edificio, de la futura Maestranza Modelo de Ferrocarriles. Estos trabajos implicaron cercar la propiedad para realizar de mejor manera estas labores, además de cerrarla para evitar el robo y la pérdida de la carga que se depositaba en ella (Moraga, 2001: 13). Esto definitivamente atentó contra el normal funcionamiento de la ciudad, significando una franca obstrucción para la fluida circulación entre los barrios oriente y poniente, ahondando los inconvenientes de segregación con los que cargó históricamente el paso del ferrocarril por San Bernardo (Ferrocarriles del Estado, febrero de 1915; 2301-2302). En este sentido, el alcalde de la ciudad solicitó en su momento al Consejo Directivo de la Empresa de Ferrocarriles "que el cierro de los andenes de la Estación de San Bernardo que se ejecuta actualmente, se haga de tal modo que no deje completamente aislada la parte oriente de la población, del resto de la ciudad", sugiriendo construir dos pasos bajo nivel que reemplacen los que hoy existen en la estación (Ferrocarriles del Estado, febrero de 1915; 2337). Es que al parecer el trazado de la línea que pasó por la ciudad se transformó en un terreno de nadie y, por lo mismo, un motivo de querella entre EFE y el municipio por quién se hacía cargo de esta propiedad prácticamente abandonada. Aprovechando el vacío urbano en que se tornaron tanto las vías ferroviarias como la estación de ferrocarriles, es que el municipio conminó a Ferrocarriles del Estado hacerse cargo de la pavimentación con "piedra de río" de la calle que corria en paralelo al oriente de la línea del tren, desentendiendo éste el fomento por el desarrollo urbano de este sector (Ferrocarriles del Estado, diembre de 1915; 1662). Si no fuera por la viuda del benefactor local don Ernesto Ducaud, quien en 1917 hace entrega a la misma municipalidad de terrenos para la construcción de una población cercana al hospital, el lado oriente del pueblo hubiera seguido esperando por su urbanización (llustre Municipalidad de San Bernardo, 1917; Vol. 90; Decreto 500). La década de 1910 coincide en mostrar un dejo de parte de las autoridades municipales por hacerse cargo de ampliar el radio 
urbano de San Bernardo hacia el lado oriente de la estación. ¿Será este el motivo por el cual a inicios de esta década surgía el amargo lamento de un vecino respecto al estado de estancamiento y retraso de este pueblo y la desazón por la eterna espera de proyectos que impulsen definitivamente su desarrollo y crecimiento local? (La Opinión, 23-VIII-1913: 2). El hecho es que con la inauguración de la Maestranza Central de Ferrocarriles en la ciudad, el $1^{\circ}$ de abril de 1920, la división espacial y el contraste urbano procuró atenuarse, pues es a partir de este recinto que se impulsa un nuevo proceso de urbanización para San Bernardo, con la construcción de nuevos barrios, calles y edificios equipados para recibir nuevos habitantes, gran parte de ellos obreros ferroviarios. Entre 1920 y 1960, el lado oriente y sur de la ciudad experimentan un auge inmobiliario que da origen a emblemáticas poblaciones obreras como la Población Sur, inaugurada en 1930, la Población Balmaceda y la Villa Ernesto Merino Segura, estas dos últimas construidas al este de la línea del tren, y todas ellas edificadas para los trabajadores maestrancinos.

El problema de la incomunicación y el aislamiento en el que vivió durante largos años el hospital de la ciudad, al situarse en la parte nororiente de la estación de ferrocarriles, pudo resolverse gracias a la construcción de nuevos barrios obreros, principalmente el de la Villa Ernesto Merino Segura, levantada sobre los antiguos terrenos de la chacra La Lata, que significó la habilitación de nuevas calles y vías que conectaron los dos lados de la ciudad y permitieron finalmente la integración del recinto hospitalario al radio urbano de San Bernardo. Respecto a esto mismo, se leía en un periódico local de la época que "tiene tan prometedoras proyecciones la construcción de esta Población [la de la Villa Ernesto Merino Segura] para nuestra ciudad, que no nos queda más que hacer fervientes votos, por que cuanto antes se lleve a la práctica. Ello traerá como consecuencia la obligada construcción de un paso bajo nivel que comunique ese sector con el Centro de San Bernardo, el que seguramente deberá hacer pasar frente a la Avenida Colón. Además se hará muy necesaria la apertura de la calle San Martín hasta el Cementerio, deseo tantas veces manifestado por los vecinos del Barrio Oriente" (El Debate; 06-VII-1946: 1).

Luego, una vez construido este conjunto habitacional, se podía ver "Al costado nororiente de la vía férrea [...] la más hermosa Población de la ciudad, que al ser observada desde el tren, se destaca por el uniforme color verde de sus techos" (La Nueva Aurora, 17-IX-1957: 6). La Villa ferroviaria Ernesto Merino Segura, bautizada así en honor a un ex Ministro de Vías y Obras Públicas, marcó el desarrollo urbano y el auge inmobiliario que el sector oriente de San Bernardo experimentó a mediados del siglo XX, fundamentalmente con la construcción de este conjunto habitacional. En las más de cien casas que darían forma a esta villa se albergaría también un grupo escolar, encargado de ofrecer educación primaria a más de 1.600 hijos de 
ferroviarios, una nutrida biblioteca, grandes áreas verdes y amplios espacios deportivos, que harían de este barrio el más moderno y avanzado de la ciudad (La Nueva Aurora, 17-IX-1957: 6). Los edificios y recintos construidos en esta villa harían de ella un activo centro cívico que convocaría también a otros vecinos de San Bernardo, dando un auge inusitado a este sector de la comuna e integrándola a las actividades diarias de ella.

Iniciado por la instalación de la Maestranza Central de Ferrocarriles, la urbanización del lado oriente de la ciudad se fue consolidando con la construcción de edificios de relevancia a nivel local. En 1944 el Gobernador del Departamento de La Victoria prevé la edificación del estadio municipal de San Bernardo en este lado de la ciudad, aprovechando la donación de terrenos hecha por la familia García de la Huerta (llustre Municipalidad de San Bernardo; Vol. 177; ff. 121-122). A esto le siguió la adquisición de una propiedad para instalar allí el nuevo cementerio de la ciudad, el cual se encontraba en las cercanías de la Villa obrera Merino Segura, tambien en los mismos terrenos de la antigua chacra La Lata (Ilustre Municipalidad de San Bernardo; Vol. 212; ff. 215-216).

\section{Conclusión}

El crecimiento de la ciudad de San Bernardo, a lo largo de más de un siglo, vino a revelar los problemas de integración social y territorial con los cuales ésta tuvo que lidiar ante el factor disruptivo en que se convirtió el paso del ferrocarril por ella. El imaginario de progreso, modernización y desarrollo atribuido al ferrocarril, en este caso se ve en entredicho, al constatar que muchos de los retrasos e inconvenientes sufridos por San Bernardo en asuntos de urbanización y espacio tuvieron que ver con el trazado de la red ferroviaria que atravesó la ciudad. Al escindir la ciudad, el paso del ferrocarril produjo dos sectores claramente delimitados, el barrio popular, obrero y marginal, ubicado al oriente de la línea del tren, y el centro cívico e histórico de la ciudad, donde habitaban los vecinos más ilustres de ella. Eso en el lado poniente de la misma. De ahí que tome relevancia lo planteado por el urbanista Patricio Gross en cuanto a que, si bien otras ciudades del sur de Chile, como San Francisco de Mostazal, Cabrero y Purranque, sí lograron desarrollarse en torno al eje ferroviario del ferrocarril al sur, San Bernardo, junto a San Carlos y Osorno, fueron centro urbanos enfrentados a la segregación espacial provocada por el paso de este medio de transporte, definiéndose en estos casos no como un eje integrador, sino al contrario, como un eje estructurador de asimetrías territoriales, que separó a la ciudad de San Bernardo en dos zonas con un desarrollo y crecimiento desigual (Gross, 1998: 12).

Junto al problema de integración territorial suscitado al paso del ferrocarril por San Bernardo, se advirtió también un grado de segregación social, el cual, 
a lo menos, fue produndizado por el sitio y por la situación de localización de la línea del tren dentro de la ciudad. A la línea férrea le correspondió ser una marca que dividió a la ciudad tradicional de los márgenes urbanos y populares de ésta. El San Bernardo ubicado al poniente de la línea de ferrocarriles era donde se localizaba el centro cívico y comercial del pueblo, sector en donde los vecinos y habitantes más connotados circulaban parsimoniosa y gentilmente, junto a los visitantes que en los meses de verano abandobaban sus cómodas casas en la capital para instalarse durante una temporada en los chalets y casas quinta que poseían en esta comuna. Mientras que al oriente de la estación y de la línea del tren se situaban los barrios más populares y proletarios de San Bernardo, muchos de ellos habitados por los obreros de la Maestranza Central de Ferrocarriles, los cuales durante la primera mitad del siglo XX impulsaron el crecimiento urbano de la ciudad al son de sus demandas y requerimientos por contar con soluciones habitacionales para sus problemas de vivienda.

En suma, a la disrrupción espacial que ocasióno el paso del ferrocarril por San Bernardo, y que generó inconvenientes asociados a la incomunicación, conectividad y marginalidad urbana, se agregó la escisión social de la ciudad, en la cual convivieron dos realidades: la de la ciudad tradicional y aristocrática, al poniente de la vía férrea, y la de la ciudad popular y obrera, al oriente de ésta, presentando un notorio contraste que rebasó los márgenes de lo propiamente urbano, que tiene que ver con el tema del crecimiento y expansión de la ciudad, para trasladarse a situaciones, impresiones y experiencias cotidianas de los sanbernardinos de antaño, quienes vivieron de manera muy tangible y concreta, e hicieron propio este rasgo de división social y espacial de la ciudad.

\section{Referencias bibliográficas}

\section{Fuentes primarias}

\section{a) Archivos}

Fondo Ministerio del Interior. Archivo Nacional de la Administración.

Fondo llustre Municipalidad de San Bernardo. Archivo Histórico de San Bernardo.

b) Prensa periódica

Boletín Municipal, San Bernardo, 1926-1927.

El Clarín, San Bernardo, 1931-1932.

El Debate, San Bernardo, 1944-1946. 
El Esfuerzo, San Bernardo, 1925-1928.

Boletín de los Ferrocarriles del Estado, Santiago, 1912-1925.

La Nueva Aurora, San Bernardo, 1957-1958.

La Opinión, San Bernardo, 1913-1950.

La Victoria, San Bernardo, 1888-1914.

\section{Fuentes secundarias}

\section{a) Artículos}

Ibarra, P. (2007-2008). "Perfil de la elite de San Bernardo a inicios del siglo XX (1900-1906)", en Anuario de Escuela de Postgrado, No 8, pp. 169-186.

Pinto, S. (1986). "Historia de los ferrocarriles en Chile. Volúmenes de carga y cantidad de pasajeros transportados (1901-1929)", en Cuadernos de Historia, $N^{\circ}$ 6, pp. 49-66.

Sagredo, R. (2000). "Fuentes para la historia de los Ferrocarriles del Estado". Chile. Siglo XIX, en América Latina en la historia económica, pp. 149-156.

\section{b) Libros}

Besoaín, R. (1995). Historia de la ciudad de San Bernardo. Santiago: Imprenta Carán.

Escobar, J. M. (1899). Memorias de Manuel J. Escobar. Caminero Mayor de la $1^{a}$ división de la $2^{a}$ sección de Santiago a Talca, en los Ferrocarriles del Estado. 1857-1899. Santiago: Imprenta de los Ferrocarriles del Estado.

Greve, N. (2012). El impacto del ferrocarril en la configuración urbana de San Bernardo. De Barrera a puente. Santiago: Escuela de Arquitectura. Universidad de Chile.

Gross, P. (1998). Desarrollo urbano y ferrocarril del sur: 1860-1960: Impactos en ciudades y pueblos de la red. Santiago: Instituto de Estudios Urbanos, PUC.

Lacoste, P. (2000). El ferrocarril trasandino 1872-1984. Un siglo de ideas, política y transporte en el sur de América. Santiago: DIBAM.

Moraga, P. (2001). Estaciones ferroviarias de Chile. Imágenes y recuerdos. Santiago: DIBAM - Consejo de Monumentos Nacionales - Centro de Investigaciones Diego Barros Arana.

Oppenheimer, R. (1976). Chilean transportation development. The railroad and socio-economic change in Central Valley, 1840-1885. Ph.D, University of California, Los Ángeles. 
Ortega, A. (2013). Rieles que unen. Patrimonio ferroviario y configuración del paisaje cultural urbano del ferrocarril al Sur entre Estación Central y San Bernardo (1905-2013). Tesis para optar al grado de Magister en Desarrollo Urbano. Santiago: Estudios Urbanos UC.

Prado, A. (1905). Única guía general de Chile 1904-1905. Santiago: Centro editorial de Alberto Prado Martínez.

Ramón, A. D. (1992). Santiago de Chile. Historia de una sociedad urbana (15411991). Madrid: Editorial MAPFRE.

Ríos, G. (1999). San Bernardo en el alma. Crónicas de sanbernardinos. Santiago: La Burbuja.

Rodríguez, F. (2007). "San Bernardo en la memoria de su gente". San Bernardo: Impresos Andrade.

Romero, J. L. (2010). Latinoamérica. Las ciudades y las ideas. Buenos Aires: Siglo XXI Editores.

Romero, L. A. (2007). ¿Qué hacer con los pobres? Elites y sectores populares en Santiago de Chile. 1840-1895. Santiago: Ariadna Ediciones.

Sagredo, R. (2001). Vapor al norte, tren al sur. El viaje presidencial como práctica politica en Chile. Siglo XIX. Santiago: DIBAM.

Santiván, F. (1955). Memorias de un tolstoyano. Santiago: Empresa Editora ZigZag.

Silvestri, G. (2004). El color del río. Historia cultural del paisaje del Riachuelo. Buenos Aires: Prometeo ediciones - Universidad Nacional de Quilmes.

Thomson, Angerstein, I. D. (2000). Historia del ferrocarril en Chile. Santiago: DIBAM.

Vicuña, S. M. (2013). Los Ferrocarriles de Chile. Santiago: Cámara Chilena de la Construcción - Pontificia Universidad Católica de Chile - DIBAM. 